\title{
Intradimensional transfer of discrimination along the hue continuum
}

This experiment investigated the intradimensional explanation for the facilitation of performance on a difficult discrimination produced by prior training on an easy problem. Significant facilitation was found only in groups given prior intradimensional training and not in groups given prior extradimensional training of equivalent difficulty.

The fact that prior training on an easy discrimination problem facilitates performance on a difficult problem more than does an equivalent amount of training on the difficult problem is well established. Mackintosh (1965) has reviewed the previous work on this problem and the finding has wide generality across species, procedures, and stimulus dimensions.

One type of explanation for the effect assumes that the relevant cues in the easy problem must be on the same dimension as the relevant cues in the hard problem in order for facilitation to occur. Such an intradimensional explanation is proposed by Lawrence (1952) and Mackintosh (1965). They assume that training on an easy problem on the same dimension increases the probability of attending to the relevant dimension during the difficult problem. In the studies cited by Mackintosh the stimuli in both problems were on the same dimension. However, Terrace (1963) demonstrated a facilitating effect when the difficulty of the training problem was varied on a dimension other than that relevant in the test problem. Therefore, it could be that problem difficulty rather than intradimensional transfer is the important factor in producing the facllitating effect. In previous studies task difficulty, the number of correct responses, the number of reinforcements, and the number of problems was varied as well as the distance along the dimension.

The present study is designed to test the intradimensional explanation proposed by Lawrence (1952) and Mackintosh (1965) by controlling for the other factors which have been confounded with distance along a dimension in previous studies.

Design

Three groups similar to those used by Lawrence (1952) were run. The hard group $(H)$ received 20 training trials and then 50 test trials on the same difficult discrimination problem. The easy group (E) recelved 20 training trials on an easy discrimination and then 50 test trials on the same difficult problem used in Group $H$. The gradual (G) group received 10 training trials on the easy problem, 10 training trials on an intermediate problem and then 50 test trials on the same difficult problem. In all these groups the stimuli in the training problem differed only in their separation on the dimension (hue) which was relevant in the test problem.

In addition to these three groups two control groups were run. The procedure used in these two groups was analogous to that used by Terrace (1963). In the easy control (E-C) group the Ss were given 20 trials on a training problem which had the same distance separating the cues as Group $H$ on the dimension (hue) relevant in the test; but which also had a large difference between the cues on the brightness dimension. A similar gradual control (G-C) group was run, but the distance along the brightness dimension was decreased with an intermediate problem as was done in Group $G$ along the hue dimension. Both these control groups received the same test problem as the preceding three groups. In the test problem there was no brightness difference and a small difference in hue between the stimuli.

\section{Subjects}

The Ss were 50 students from an introductory psychology course who chose participation in an experiment as an option for satisfying a course requirement.

Apparafus

The stimuli were hue chips from the Munsell book of color. The stimuli for all groups during the $\mathbf{5 0}$ test trials were $10 \mathrm{G} 6 / 8$ and $2.5 \mathrm{BG} 6 / 8$. Other training stimuli used in experimental groups differed from the test stimuli only on the hue dimension (5 BG$6 / 8,7.5 \mathrm{BG}-6 / 8,7.5 \mathrm{G}-6 / 8$, and $5 \mathrm{G}-6 / 8)$. The training stimuli used in the control groups were the same as the test stimull on the hue dimension but different in brightness $(10 \mathrm{G}-5 / 8,10 \mathrm{G}-4 / 8,2.5 \mathrm{BG}-5 / 8,2.5 \mathrm{BG}-$ 4/8).

The stimuli were presented to the Ss in the center of a black surround in a Gerbrands tachistoscope (Model T-1C). The exposure duration was $1 \mathrm{sec}$ and the rated light output was $105 \mathrm{~lm}$. A white preexposure field was used.

\section{Procedure}

Ten Ss were randomly assigned to each of the five groups in the order of their appearance in the laboratory (with the restriction of equal $\mathrm{Ns}$ in each group). The Ss were pretested for color vision with selected plates from the Drorine color testing plates. One $\mathrm{S}$ was discarded for fallure to read the color plates. The Ss were instructed that the experiment was 
Table 1. Mean number of correct responses in the training and test in Experiment 1.

\begin{tabular}{llllcc} 
Group & Hard Easy & Gradual & Grad.-Control & Easy-Control \\
\hline $\begin{array}{c}\text { Mean no. correct } \\
\text { in training }\end{array}$ & 10.2 & 18.3 & 18.9 & 19.0 & 19.0 \\
$\begin{array}{c}\text { Mean no. correct } \\
\text { in test }\end{array}$ & 25.2 & 37.6 & 38.8 & 27.7 & 25.2 \\
\hline
\end{tabular}

concerned with color discrimination and that they would be shown the correct stimulus five times and then other incorrect stimuli would be shown. The Ss were told to respond by saying "yes" to the correct stimulus and "no" to any other (incorrect) stimulus.

The Ss were then given five pretraining exposures to the sorrect stimulus. Following this the correct and incorrect stimuli were presented alone on successive trials according to the Gellerman orders. The Ss were reinforced by E saying "right" or "wrong" for each response. In all groups the positive stimulus was counterbalanced within the group and the positive stimulus was constant from training to the test problem. The conditions under which the five groups were run are described in the design section.

\section{Results}

The mean number of correct responses made by the various groups during the 20 training trials is shown in Table 1. In both the gradual (G and $G-C$ ) and easy ( $E$ and $E-C$ ) groups the number of errors is minimal and these four groups do not differ significantly in the mean number of correct responses made during training ( $F>1$ ). These four groups do differ significantly from Group $H$ by Dunnett's test (Edwards, 1960, p. 152) ( $p<.01)$.

The mean number of correct responses during the 50 test trials is also shown in Table 1. A factorial analysis of variance was carried out on the four groups which had different training and test problems (G, G-C, E and E-C). The two factors were Gradual vs Easy and Experimental vs Control.

The main effect for the Experimental vs Control conditions was significant $(F=63.95, d f=1 / 36, p<.001)$.

The main effect for the Easy vs Gradual conditions was not significant $(F=1.59, \mathrm{df}=1 / 36, p>.10)$, nor was the interaction between the factors ( $F>1$ ).

A comparison of the mean number correct in the 50 test trials in Group $H$ with the mean number correct in the other four groups by Dunnett's test showed that Groups $E$ and $G$ differed significantly $(p<.01$ two-tailed) from Group $\mathrm{H}$ while Groups E-C and G-C did not differ significantly from Group $H$.

\section{Discussion}

The fact that the four groups (E, G, E-C and G-C) did not differ significantly on the number of correct responses during the 20 training trials means that these groups were equivalent with regard to the task difficulty of the training problem, the number of correct responses, and the number of reinforcements. In addition the experimental and control groups were equated on the number of training problems. Only the experimental groups given the intradimensional transfer problems showed any significant facilitation on the difficult problem. The results of the present experiment, therefore, tend to support Lawrence's (1952) and Mackintosh's (1965) intradimensional explanation for the facilitation found in transfer from an easy to a hard discrimination problem.

In contrast to the present study Baker \& Osgood (1954), who also used human adults as $\mathrm{Ss}$, found no facilitation in the easy condition but did find facilitation in the gradual condition. Although the present study differs from Baker and Osgood's in a number of ways, it seems likely that two aspects of their procedure produced this discrepancy. Baker and Osgood used a same-different response and did not provide reinforcement (informative feedback) during the test period.

\section{References}

Baker, R. A., \& Osgood, S. W. Discrimination transfer along a pitch continuum. J. exp. Psychol., 1954, 48, 241-246.

Edwards, A. L. Experimental design in psychological reseatch. New York: Holt, 1960.

Lawrence, D. H. The transfer of a discrimination along a continuum. J. comp. physiol. Psychol., 1952, 45, 511-516.

Mackintosh, N. J. Selective attention in animal discrimination learning. Psychol. Bull., 1965, 64, 124-150.

Terrace, H. S. Discrimination learning with and without "errors." J. exp. Anal. Behav., 1963, 6, 223-232. 